\title{
Lipids study of Caranx rhonchus in Mauritanian Atlantic
}

\author{
1,2," Khalihena Groune, A.L., ${ }^{2}$ Med Lemine, B., ${ }^{1}$ Adnane, E.H. and ${ }^{1}$ Mohammed, H. \\ ${ }^{1}$ Laboratory of Nanomaterials, Nanotechnologies and Environment, Center of Materials Science, Faculty of \\ Sciences, Mohammed V University, Ibn Battouta Avenue, P.O.Box : 1014, 10000, Rabat, Morocco \\ ${ }^{2}$ Laboratory of Food Chemistry, Superior Institute of Marine Science, Naval Academy, Marine Avenue, \\ P.O.Box : 28, Nouadhibou, Mauritania
}

\author{
Article history: \\ Received: 12 August 2020 \\ Received in revised form: 10 \\ September 2020 \\ Accepted: 9 November 2020 \\ Available Online: 21 \\ February 2021 \\ Keywords: \\ Caranx rhonchus, \\ False horse mackerel, \\ Fish oil, \\ Fatty acids, \\ Gas chromatography
}

\begin{abstract}
In order to assess the quantity and quality of lipids in the Caranx rhonchus in Mauritanian Atlantic, we carried out analytical studies (FTIR-ATR analysis and chromatographic analysis) of lipids and fatty acids. The results revealed that the studied samples are generally rich in lipids: 11,39 and $31,49 \%$. The fatty acids of the lipids of the samples studied are subdivided into three essential groups: polyunsaturated fatty acids, monounsaturated fatty acids and saturated fatty acids. The results showed that the Caranx rhonchus in Mauritanian Atlantic is very rich in monounsaturated fatty acids (oleic acid, palmitoleic acid and vaccenic acid) in comparison with the polyunsaturated (eicosapentaenoic acid and docosahexaenoic acid) and saturated fatty acids.
\end{abstract}

DOI:

https://doi.org/10.26656/fr.2017.5(5).430

\section{Introduction}

Mauritania is a country in the Sahel with a coastline of $750 \mathrm{~km}$, an exclusive Mauritanian economic zone that covers $234000 \mathrm{~km}^{2}$, about $16 \%$ of the continental shelf. Between Cape Blanc and Cape Timiris, the continental shelf extends up to 80 miles from the coast, while to the south it reaches only 30 miles. The continental shelf of $39,000 \mathrm{~km}^{2}$, presents a great diversity of fish resources. Approximately 600 species have been identified, of which 200 can be exploited commercially. Mauritanian waters are very productive because they are very rich in fish resources thanks to the nutrients transported by the marine current of the canaries and the natural rise of cold waters. However, most of these resources are destined for export and the population's levels of fish consumption are very low compared to a country with a very important seaboard (Kinadjian et al., 2015).

In the Mauritanian Exclusive Economic Zone, small pelagic fish are exploited almost exclusively by foreign long-haul fleets, chartered or licensed, under bilateral agreements and /or joint ventures (Kinadjian et al., 2015).

The production of small pelagic species exported in raw form is thus fully engaged in the world trading system. Such a configuration contributes to the strengthening of the extraversion of the economy of small pelagic fisheries, which could limit the supply of local markets and the contribution to the economy in general.

From the year 2010, the Mauritanian state wanted to perpetuate the fish distribution business with the $2 \%$ obligation applied to the landings of pelagic vessels working under the EU-Mauritania fisheries agreements without requiring the recourse to confiscated products.

This is why the creation of the National Society of Fish Distribution has become a priority for the Mauritanian state since 2011. Through its positive contributions to the food security policy, the National Fish Distribution Company is establishing to promote the consumption of fish by facilitating the access conditions of the Mauritanian populations to these products.

The National Fish Distribution Company sells mainly two species (horse mackerel and round sardinella) with the vast majority of horse mackerel including Cunene horse mackerel (Trachurus trecae) Atlantic horse mackerel (Trachurus trachurus), and the false horse mackerel or the false scad (Caranx rhonchus or Decapterus rhonchus), the latter is the subject of our 
study.

The Caranx rhonchus in the Mauritanian Atlantic is of great socio-economic interest for the food security in the country. Indeed, this species is a product of great commercial value. They are valuable marine foodstuff with many benefits regarding human nutrition. They are very rich in energy sources such as proteins and highquality lipids that contain monounsaturated and polyunsaturated essential fatty acids that have very high biological and nutritional values. The diet changes with season and size (Sley et al., 2008).

These lipids also constitute a raw material of excellent energetic and therapeutic quality for the enrichment of foods. This type of fatty acid protects the vessels from cholesterol (Baker and Gibbons, 2000), plays a role in the prevention of cardiovascular disease (Saee et al., 1999; Nordoy et al., 2001).

The consumption of these species lowers cholesterol levels in blood plasma (Bledsoe et al., 2003). It improves learning ability (Yonekubo et al., 1994; Lim and Suzuki, 2002). Polyunsaturated fatty acids have an influence on the levels of two blood lipids: cholesterol and triglycerides. Fish lipids are a significant source of energy and structural components required for reproductive development (Noctron and Macfarlane, 1999). Recent studies have clearly shown the importance of omega-3 and omega- 6 fatty acids for human health and nutrition (Connor, 2000). Fortunately, fish oil is one of the best sources of dietary supply of these fatty acids. Oils and fats used for human consumption are natural components of vegetables and land or marine origin animals (Rafflenbeul, 2001). Regardless of sources, principal components of these oils and fats are the same. They are triglyceride oils in that their principal constituents, amounting, usually to over $90 \%$ of their total composition, are the tri-esters of fatty acids and glycerol. The remainder of their composition consists of partial glycerides, such as mono- and di-glycerides, free fatty acids (FFA) and other compounds, in small quantities. The differences between the various oils and fats lie in the fatty acid composition of the triglycerides and phosphatides, and in the composition of the unsaponifiable fraction other minor compounds (Young, 1986). Fish species contain oil in different amounts, varying according to species, age, gender, location, and species-origin characteristics, such as spawning and migration seasons, and some environmental conditions, such as temperature (Boran et al., 2006).

Two polyunsaturated fatty acids are essential: linoleic acid and linolenic acid. These two fatty acids are provided by the oil and transformed in the body into other fatty acids, in particular arachidonic acid (AA), eicosapentaenoic acid (EPA) and docosahexaenoic acid (DHA) (Raz et al., 1998). These polyunsaturated fatty acids, especially linoleic acid, play a role in the constitution of cell membranes. This explains their importance in the growth phase due to the multiplication of cells (Bentsen, 2017). As well, the ratio of omega- 6 to omega-3 fatty acids is considered as a biomarker for many clinical conditions such as breast cancer, coronary cancer, and cardiac arrest has become an issue of concern to many researchers (Simopoulos and Cleland, 2003; Purdie et al., 2011).

Because of the great economic value and interest in human health, we delve into this study so as to gain detailed information on lipid composition in the Caranx rhonchus in the Mauritanian Atlantic.

\section{Materials and methods}

\subsection{Fish species}

The Caranx rhonchus (or Decapterus rhonchus), also known as Comète cossue (or Chinchard jaune) in French, Jurel in Spanish and False scad (or false horse mackerel and or yellow horse mackerel) in English, is a species of medium-sized marine fish classified in the family Carangidae (Romero, 2002). It is distributed in the eastern Atlantic of Angola to Morocco including Mauritania along the African coast and reaching as far north as Spain in Europe, with its range also extending well into the Mediterranean Sea (Figure 1) (Bauchot, 2003). It is an opportunistic fish whose diet is characterized by a great diversity of species (Small fish and invertebrates). Distinguishing the species from members of Caranx rhonchus and horse mackerel is more difficult; the latter is also very widespread in Mauritania.

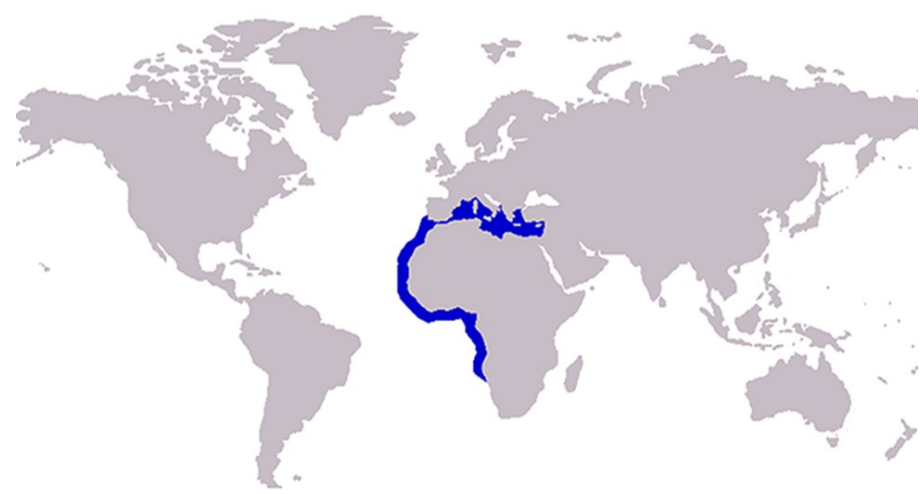

Figure 1. Distribution range colors indicate the degree of suitability of habitat which can be interpreted as probabilities of occurrence (Bauchot, 2003)

In Mauritania, it is probably present all year in the Exclusive Mauritanian Economic Zone. Its distribution is 
more coastal and more southerly than the other species of horse mackerel. Its abundance increases from Cape Timiris to the south. These species also migrate along the coasts, from Guinea to Mauritania at the rhythm of the seasonal swing of the intertropical front. It is absent during the first half of the northern zone. In the warm season, young individuals are present in the shallow waters of the south of Cape Timiris. Most of the biomass located on the bottom is of less than $100 \mathrm{~m}$. At the beginning of the cold season (October-November), the biomass is located mainly on the $50 \mathrm{~m}$ depth south of Cape Timiris (Josse, 1989).

The Caranx rhonchus can be caught using pelagic bottom trawls, purse seines and fixed nets. Caranx rhonchus: Maturity: $\mathrm{L}_{\mathrm{m}} 24.7 \mathrm{~cm}$; range $24-49.5 \mathrm{~cm}$; Max length: $60.0 \mathrm{~cm}$; common length: $35.0 \mathrm{~cm}$, Weight: $0.37-0.8 \mathrm{~kg}$ (max: $2 \mathrm{~kg}$ ), max age: 7 years (Bauchot, 2003).

\subsection{Samples preparation}

The fresh fish under study (Caranx rhonchus) was purchased from the fishermen on the beach (about 4-5 $\mathrm{kg}$ ) which was in a sexually mature state.

For the study of the quality and quantity of the total fats of Caranx rhonchus in Mauritania, we used the following procedure: the fish was transported to the laboratory (Figure 2), sliced washed (cleaned) with cold water, eviscerated and filleted immediately. For this study, two samples for two species were selected (Table 1). The two samples were dried at $105 \pm 2{ }^{\circ} \mathrm{C}$ until reaching constant weight (Table 1) then crushed, minced and homogenized separately.

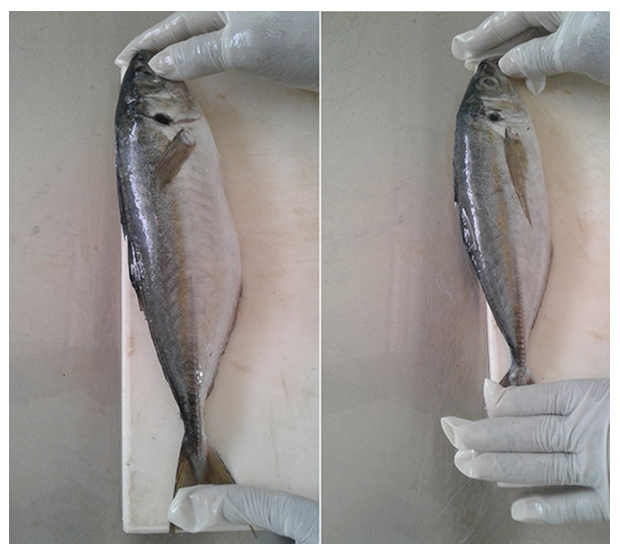

Figure 2. View for the studied species

Table 1. Weights of the samples during the preparation

\begin{tabular}{ccc}
\hline & Caranx 1 & Caranx 2 \\
\hline W1 & $205 \mathrm{~g}$ & $235 \mathrm{~g}$ \\
W2 & $185 \mathrm{~g}$ & $205 \mathrm{~g}$ \\
W3 & $65 \mathrm{~g}$ & $95 \mathrm{~g}$ \\
\hline
\end{tabular}

W1: weight at the beginning; W2: weight after slicing and cleaning, W3: weight after oven drying

\subsection{Lipid extraction (fish oil) and transesterification}

In order to obtain sufficient fish oil (lipids), all samples were continually used for extraction until the desired amount was collected. For this purpose, a Soxhlet system was used for semi-continuous extraction (at a rate of 7 cycles $/ \mathrm{hr}$, during $8 \mathrm{hrs}$ ) and chloroform/ methanol $(1: 1 \mathrm{v} / \mathrm{v})$ were used as solvents. Table 2 shows the amount of lipids for each sample studied. The lipids can be classified into:

- Saponifiable lipids containing fatty acids such as acylglycerols, phosphoglycerides and waxes. They are saponifiable until they provide soaps after alkaline hydrolysis.

- Unsaponifiable lipids not containing fatty acids. There are two main types: sterols and terpenes.

A good quality food oil consists of over 98\% triglycerides. Those are tri-esters of glycerol and fatty acids. Homogeneous triglycerides and heterogeneous triglycerides are distinguished.

The saponification index is expressed by potassium hydroxide (or sodium hydroxide) in $\mathrm{mg}$ required to saponify $1 \mathrm{~g}$ of fat. It depends on the kind of fatty acid contained in the oil.

Table 2. Extracted amount of the lipids from the samples

\begin{tabular}{cccc}
\hline Samples & W1 & W2 & \% lipids \\
\hline Caranx 1 & $25.01 \mathrm{~g}$ & $22.16 \mathrm{~g}$ & 11.39 \\
Caranx 2 & $25.02 \mathrm{~g}$ & $17.14 \mathrm{~g}$ & 31.49 \\
\hline
\end{tabular}

W1: weight at the beginning; W2: weight after slicing and cleaning

The sample 1.5 to $2.0 \mathrm{~g}$ was first saponified by adding $25.0 \mathrm{~mL}$ of $0.5 \mathrm{~mol} / \mathrm{L}$ potassium hydroxide ethanol, and then the excessive potassium hydroxide was titrated with $0.5 \mathrm{~mol} / \mathrm{L}$ hydrochloric acids until the endpoint reached.

Before analysis, the fatty acids should be converted into methyl esters by esterification of the lipids (Christie and Han, 2010): The lipid sample (up to $1 \mathrm{~g}$ ) was dissolved in toluene $(20 \mathrm{~mL})$ in a test tube fitted with a condenser, and $0.4 \mathrm{~mL}$ sulfuric acid in methanol ( $40 \mathrm{~mL})$ was added before the mixture was refluxed for $2 \mathrm{hrs}$. Water $(100 \mathrm{~mL})$ containing sodium chloride $(5 \mathrm{~g})$ was added and the required esters were extracted with hexane (200 $\mathrm{mL}$ ) using decantation system to separate the layers. The hexane layer was washed with water $(80 \mathrm{~mL})$ containing potassium bicarbonate $(2 \%, 1.6 \mathrm{~g})$ and dried over anhydrous sodium sulfate. The solution was then filtered to remove the drying agent, and the solvent was removed under reduced pressure in a rotary film evaporator. 


\subsection{Chemical analysis}

\subsubsection{FTIR-ATR analysis}

Fourier Transform Infra-Red in conjunction with Attenuated Total Reflectance (FTIR-ATR) spectroscopy was performed to identify qualitatively the organic materials present in the samples by observing their characteristic absorption bands. The spectra were recorded using a Jasco FT/IR 4600 spectrometer provided with ATR (Pro One) module. The samples were scanned in transmission mode with $4 \mathrm{~cm}^{-1}$ resolution at the range $4000-400 \mathrm{~cm}^{-1}$ and atmospheric correction switched on at room temperature $\left(25^{\circ} \mathrm{C}\right)$.

\subsubsection{Chromatographic analysis}

The analysis of the methyl esters was carried out on a coupled phase chromatograph with mass spectrometer (GC/MS) equipped with a flame ionization detector. They were separated on an Rxi-5Sil capillary column (30 $\mathrm{m} \times 0.25 \mathrm{~mm}$ i.d.). Flow rate column was $1 \mathrm{~mL} / \mathrm{min}$. The column temperature was programmed from $140^{\circ} \mathrm{C}$ to $240^{\circ} \mathrm{C}$ at a rate of $5^{\circ} \mathrm{C} \mathrm{min}^{-1}$ and held for 30 mins at $300^{\circ}$ C. Ionization was performed at electron impact $(70 \mathrm{eV})$.

The compounds of fatty acids were identified on the basis of their GC retention times and by comparisons of their mass spectra with those of standards and with data from the literature.

\section{Results and discussion}

\subsection{Lipid extraction}

This study shows that the lipid content of whole fish between 11, 39 and 31, 49\% for the fish studied (Table 2). Our results generally showed that Caranx rhonchus in Mauritanian Atlantic is rich in lipids. The reproduction status for Caranx 1 sample at the time of our sampling justifies the very low lipid content compared to Caranx 2 sample, which apparently is a male.

\subsection{Saponification index}

The saponification index value was found to be $147-$

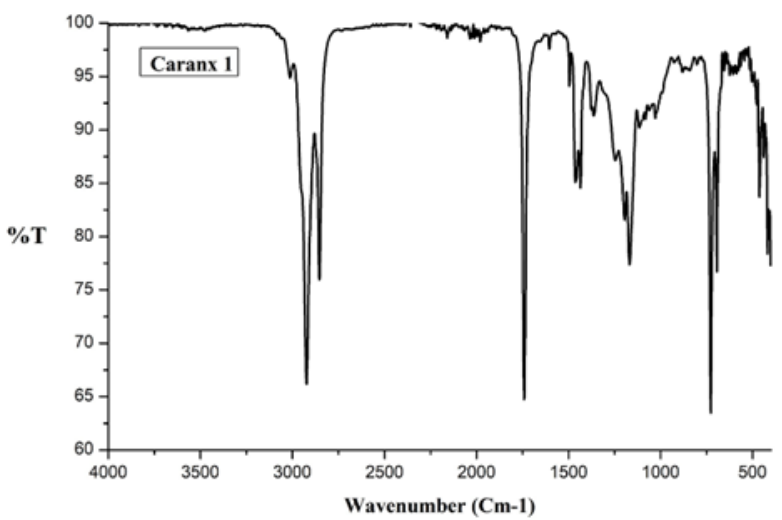

$157 \mathrm{mg} \mathrm{KOH} / \mathrm{g}$; these values fall within the acceptable standard values (Adeniyi and Bawa, 2006). Based on this characteristic of this fish oil (lipids), it would be suitable for food security.

\subsection{FTIR analysis}

The Fourier transform infrared spectroscopic technique (ATR-FTIR) is a rapid method for the determination of fatty acid contents in an extracted fishoil. Using the ATR-FTIR technique, the samples can be directly analyzed without any pre-treatment required (Hormoz et al., 2004; Vongsvivut et al., 2012). In addition, the subsequent predictions acquired from an independent validation set for the target fatty acid compositions (i.e., total oil, total $\omega-3$ fatty acids and total $\omega-6$ fatty) were highly accurate when compared to the actual values obtained from standard GC-based technique. The study, therefore, demonstrated not only the substantial advantage of the ATR-FTIR technique in terms of rapidness and cost effectiveness but also its potential application as a rapid, potentially automated, for the routine analysis of fatty acid composition.

Figure 3 shows the FTIR-ATR spectrum of extracted lipids (fish oil), after the transesterification of the fatty acids, of the studies of the samples from Caranx rhonchus in Mauritanian Atlantic. In the range from 3050 to $2750 \mathrm{~cm}^{-1}$, the bands correspond to asymmetric and symmetric stretching vibrations of the methyl and methylene groups. The asymmetric and symmetric bands of the methyl groups were labelled as $(\mathrm{CH} 3)$. Their maxima occur at wavenumbers 2958 and $2868 \mathrm{~cm}^{-1}$, whereas asymmetric and symmetric bands of methylene groups labelled as (CH2) occur at 2920 and $2852 \mathrm{~cm}^{-1}$ (Petibois and Déléris, 2006).

A peak at $\approx 1750 \mathrm{~cm}^{-1}$ corresponds to the stretching vibration of the ester function of the $\mathrm{C}=\mathrm{O}$ group, which corresponds to the transesterification of the fatty acids in the extracted lipids (fish oil). In the range from 1500 to $1650 \mathrm{~cm}^{-1}$, a peak corresponds to the stretching vibrations of the $\mathrm{C}=\mathrm{C}$ group (Petibois and Déléris, 2006).

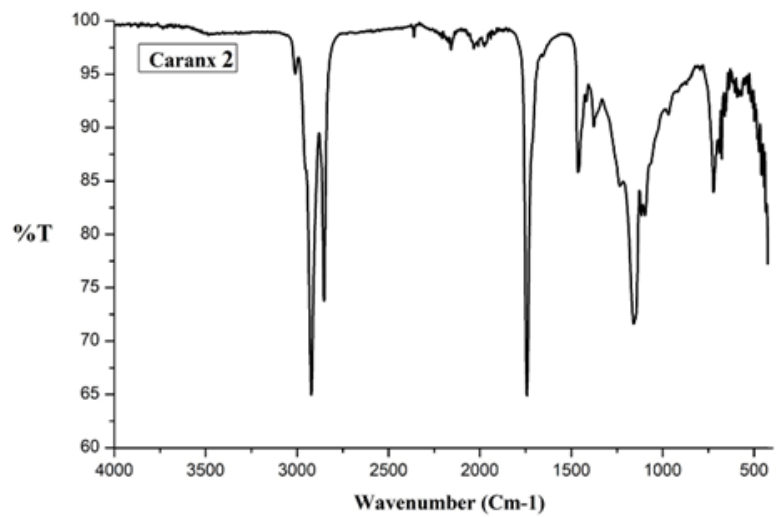

Figure 3. FTIR-ATR spectrum of extracted lipids (fish oil) of the fish studied 
A peak at $\approx 1460 \mathrm{~cm}^{-1}$ corresponds to the deformation vibration of the two groups - $\mathrm{CH} 2$ and - $\mathrm{CH} 3$ and a peak at $\approx 1375 \mathrm{~cm}^{-1}$ attributed specifically to the asymmetric deformation vibration of the - $\mathrm{CH} 3$ group. The ratio of the intensities of these two peaks $\left(1460 \mathrm{~cm}^{-1}\right.$ and 1375 $\mathrm{cm}^{-1}$ ) equals $\approx 1.9$ reflects the presence of relatively long chains (the case of fatty acids).

\section{$3.4 \mathrm{GC} / \mathrm{MS}$ analysis}

The Gas chromatography (GC) is a highly sensitive method used to identify and quantify the fatty acid content of lipids, as is the case with fish oil. Solid phase extraction using Soxhlet system allows separation of the major lipid classes including triacylglycerols, different phospholipids, and cholesteryl esters. The gas chromatography (GC) coupled with mass spectrometer (MS) was used to analyze the fatty acid composition in the Caranx rhonchus in Mauritanian Atlantic (Figure 4).

The chromatogram shows a quantitative difference in the fatty acid content of Caranx rhonchus in Mauritanian Atlantic and the majority of monounsaturated fatty acids are: palmitoleic acid (C16:1 w7) which is very high, $22,40 \%$, in Caranx 1 sample, flowed by Vaccenic acid $(\mathrm{C} 18: 1 \omega 7)$ and oleic acid (C18:1 $\omega 9), 14,03 \%$ and $13,63 \%$ successively.

On the contrary, the oleic acid $(\mathrm{C} 18: 1 \omega 9)$ is very high, 20, 94\%, in Caranx 2 sample, flowed by palmitoleic acid (C16:1 $\omega 7)$ and Vaccenic acid (C18:1 $\omega 7), 20,38 \%$ and $09,60 \%$ successively.

In addition, it shows other polyunsaturated fatty acids (omega-3), the most important of which is docosahexaenoic acid (DHA) (C22:6 $\omega 3)$, eicosapentaenoic acid (EPA) (C20:5 $\omega 3$ ), both are also very high in Caranx rhonchus in Mauritanian Atlantic. The quantitative values of eicosapentaenoic acid (EPA) of the studied samples are 5, 19\% and 5, 45\% for Caranx 1 and Caranx 2 samples successively. By cons for the docosahexaenoic acid (DHA),

The quantitative values of the studied samples are 8, $47 \%$ and 5,71\% for Caranx 1 and Caranx 2 samples successively.

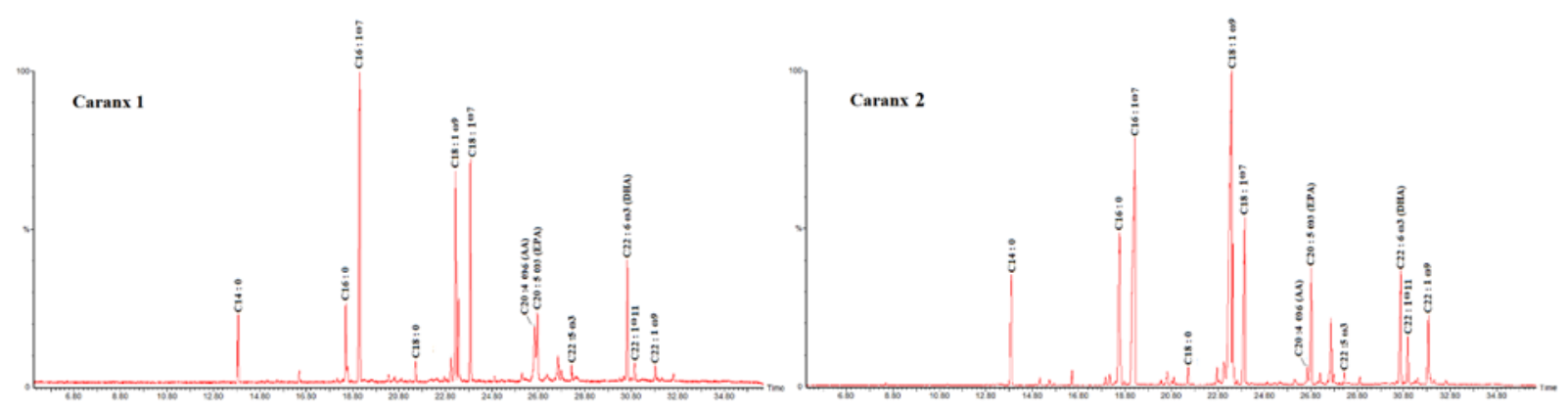

Figure 4. Chromatogram of extracted lipids (fish oil) of the fish studied
In general, the monounsaturated fatty acids are more important than the polyunsaturated fatty acids and saturated fatty acids.

The linoleic acid (LA) (C18:2 $\omega 6)$ and $\alpha$-linolenic acids (ALA) (C18:3 $\omega 3)$, which are the precursors for the omega-6 and omega-3 polyunsaturated fatty acids successively, are very low in the studied samples.

\section{Conclusion}

This work focused on qualitative and quantitative lipids analysis the Caranx rhonchus in the Mauritanian Atlantic. In the first part, we determined the fat content; the results showed that Caranx rhonchus in the Mauritanian Atlantic Ocean is rich in lipids which were confirmed by the saponification index (SI) and FTIRATR analysis. In the second part, we were interested in fatty acid analyses in lipids. The chromatographic analysis shows that the majority of fatty acids are monounsaturated fatty acids: palmitoleic acid (C16:1 $\omega 7$ ) in Caranx 1 sample, and oleic acid (C18:1 $\omega 9)$ in Caranx 2 sample. For the polyunsaturated fatty acids (omega-3), the docosahexaenoic acid (DHA) (C22:6 $\omega 3$ ) and eicosapentaenoic acid (EPA) (C20:5 133$)$ are very less in Caranx rhonchus in the Mauritanian Atlantic in front the monounsaturated fatty acids.

\section{Conflict of interest}

The authors declare that they have no known competing financial interests or personal relationships that could have appeared to influence the work reported in this paper.

\section{Acknowledgements}

The authors thank the Center of Materials Sciences, Faculty of Science, Mohammed V University, Rabat, for their assistance in analyzing our samples. The authors also thank the Cooperation and Cultural Action Service. French Embassy in Mauritania and the Deep Blue project for financial support for the movement and conduct research.

\section{References}

(C) 2021 The Authors. Published by Rynnye Lyan Resources 
Adeniyi, O.D. and Bawa, A.A. (2006). Mackerel (Scomber Scrombrus) Oil Extraction and Evaluation as Raw Materials for Industrial Utilization. Leonardo Journal of Sciences, January-June 2006(8), 33-42.

Baker, P.W. and Gibbons, G.F. (2000). Effect of dietary fish oil on the sensitivity of hepatic lipid metabolism to regulation by insulin. Journal of Lipid Research, 41(5), 719-727. https://doi.org/10.1016/S0022-2275 (20)32380-4

Bauchot, M.L. (2003). Carangidae. In Lévêque, C., Paugy, D. and Teugels, G.G. (Eds.). p. 464-483. Faune des poissons d'eaux douce et saumâtres de l'Afrique de l'Ouest, Tome 2., p. 464-483. Paris, France : Institut Français De Recherche Scientifique Pour Le Développement En Coopération. [In French].

Bentsen, H. (2017). Dietary polyunsaturated fatty acids, brain function and mental health. Microbial Ecology in Health and Disease, 28(Supplementary 1: Nobel Forum Symposium: Science Meets Industry - the Food and the Mood, 1281916. https:// doi.org/10.1080/16512235.2017.1281916

Bledsoe, G.E., Bledsoe, C.D. and Rasco, B. (2003). Caviars and fish roe products. Critical Reviews in Food Science and Nutrition, 43(3), 317-356. https:// doi.org/10.1080/10408690390826545

Boran, G., Karaçam, H. and Boran, M. (2006) Changes in the quality of fish oils due to storage temperature and time. Food Chemistry, 98(4), 693-698. https:// doi.org/10.1016/j.foodchem.2005.06.041

Christie, W.W. and Han, X. (2010). Lipid Analysis Isolation, Separation, Identification and Lipidomic Analysis, 4th ed. USA: Woodhead Publishing Limited.

Connor, W.E. (2000). Importance of n-3 fatty acids in health and disease. The American Journal of Clinical Nutrition, 71(1), 171S-175S. https:// doi.org/10.1093/ajen/71.1.171S

Josse, E. (1989). Les ressources halieutiques de la ZEE mauritanienne. Description, évaluation et aménagement. Rapport du deuxième groupe de travail CNROP/FAO/ORSTOM. Rome : FAO. [In French].

Hormoz, A., John, K.G.K., Anthony, R.K., Marta, H., Magdi, M.M. and Suzanna, L. (2004). Winsborough, Quantification of trans fatty acids in food products by GC, ATR-FTIR and FT-NIR methods. Lipid Technology, 16(10), 229-231.

Kinadjian, L., Soumaré, A. and Naffa, M.L. (2015). Final report on the investment framework for the sustainable development of fisheries in Mauritania, 2015 - 2020. Government of the Islamic Republic of
Mauritania: Ministry of Fisheries and Maritime Economy.

Lim, S.Y. and Suzuki, H. (2002). Dose-response effect of egg phosphatidylcholine on maze-learning ability and fatty acid composition of plasma and brain in aged mice fed an n-3 fatty acid-deficient diet. Annals of Nutrition and Metabolism, 46, 215-221. https:// doi.org/10.1159/000065410

Noctron, E. and Macfarlane, R. (1999). Lipid class composition of the viviparous yellowtail rockfish over a reproductive cycle. Journal of Fish Biology, 957(54), 1287- 1299. https://doi.org/10.1111/j.10958649.1999.tb02055.x

Petibois, C. and Déléris, G. (2006). Chemical mapping of tumor progression by FT-IR imaging: towards molecular histopathology. Trends in Biotechnology, 24(10), 455-462. https://doi.org/10.1016/ j.tibtech.2006.08.005

Purdie, N., Reilly, L., Muriuki, M.W. and Dumancas, G.G. (2011). Quantification of total omega-6, total omega-3 and omega-6/omega-3 ratio in human serum using GC/MS. LCGC North America, 29, 6067.

Rafflenbeul, W. (2001). Fish for a healthy heart. European Journal of Lipid Science and Technology, 103(5), 315 - 317. https://doi.org/10.1002/14389312(200105)103:5<315::AID-EJLT315>3.0.CO;2$\mathrm{H}$

Raz, A., Kamin-Belsky, N., Przedecki, F. and Obukowicz, M. (1998). Dietary fish oil inhibits $\omega 6-$ Desaturase Activity in vivo. Journal of American Oil Chemists Society, 2(75), 241-245. https:// doi.org/10.1007/s11746-998-0037-4

Romero, P. (2002). An etymological dictionary of taxonomy. Madrid [Unpublished].

Saee, S., Suhur, S. and Nazlin, H. (1999). High performance liquid chromatography and spectroscopic studies on fish oil oxidation products extracted form frozen Atlantic mackerel. Journal of the American Oil Chemists Society, 76(3), 391-397. https://doi.org/10.1007/s11746-999-0247-4

Simopoulos, A.P. and Cleland, L.G. (2003). Importance of the ratio of Omega-6/Omega-3 Essential Fatty Acids: Evolutonary Aspects. In Omega-3 Essential Fatty Acid Ratio: The Scientific Evidence. Basel, Canada: Karger. https://doi.org/10.1159/isbn.978-3318-01018-3

Sley, A., Jarboui, O., Ghorbel, M. and Bouain, A. (2008). Diet composition and food habits of Caranx rhonchus (Carangidae) from the Gulf of Gabes (Central Mediterranean). Journal of the Marine Biological Association of the United Kingdom, 88 
(4), $\quad$ 831-836. https://doi.org/10.1017/

S0025315408001379

Vongsvivut, J.I., Heraud, P., Zhang, W., Kralovec, J.A., McNaughton, D. and Barrow, C.J. (2012). Quantitative determination of fatty acid compositions in micro-encapsulated fish-oil supplements using Fourier transform infrared (FTIR) spectroscopy. Food Chemistry, 135(2), 603-609. https://doi.org/10.1016/j.foodchem.2012.05.012

Yonekubo, A., Honda, S., Okano, M., Takahashi, K. and Yamamoto, Y. (1994). Effect of dietary fish oil during the fatal and postnatal periods on the learning ability of postnatal rats. Bioscience Biotechnology and Biochemistry, 58(5), 799-801. https:// doi.org/10.1271/bbb.58.799

Young, F.V.K. (1986). The refining and hydrogenation of fish oil. Fish Oil Bulletin No. 17, p. 1-27. Hertfordshire, England: International Fishmeal and Fish Oil Organisation. 